\title{
Aceitabilidade dos tecnólogos no mercado de trabalho: a realidade da microrregião de Chapecó/SC
}

\author{
Humberto Tonani Tosta ${ }^{1}$ \\ Fábio Martins Moreira ${ }^{2}$ \\ Adriano Moraes $^{3}$ \\ Dayane da Silva Wolmann ${ }^{4}$ \\ Lenusa Paulina Biazin ${ }^{5}$ \\ Lilian Michele Jung ${ }^{6}$ \\ Sirlei Zanco Regoso ${ }^{7}$ \\ Reginaldo José da Silva ${ }^{8}$
}

\section{RESUMO}

Análise das características do mercado de trabalho e, especificamente, investigação da demanda por profissionais de gestão de nível superior tecnológico na microrregião de Chapecó, situada a oeste do estado de Santa Catarina. Estudo de abordagem qualitativa e quantitativa e, quanto aos fins, caracterizado como pesquisa exploratória e descritiva. A análise dos dados utilizou a estatística descritiva e interpretações qualitativas. A pesquisa apontou a demanda por profissionais de gestão de pessoas, processos gerenciais, tecnologia da informação, gestão financeira, gestão da qualidade, gestão comercial e logística. Os resultados sinalizam o interesse entre os empresários, especialmente nas indústrias, pela modernização e pela busca de vantagem competitiva por meio da contratação de profissionais capacitados.

Palavras-chave: Mercado de trabalho. Profissionais de nível superior tecnológico. Indústrias da microrregião de Chapecó.

\section{DELIMITAÇÃO DO TEMA E DO PROBLEMA DA PESQUISA}

Na sociedade do conhecimento, o ser humano passa a ser o ativo mais importante das organizações. Dessa maneira, estas devem buscar caminhos para se tornarem atrativas e para conseguirem reter seu capital humano.

No entanto, no cenário que se apresenta, os trabalhadores do conhecimento devem ser os atores principais de sua formação; para isso, devem estar em constante desenvolvimento. Somente com essa postura eles se tornarão e se manterão atrativos para o mercado de trabalho.

No que tange à formação de nível superior, com o objetivo de formar pessoas com formação adequada às necessidades do mercado de trabalho, no Brasil, uma alternativa que vem atendendo tal demanda são os

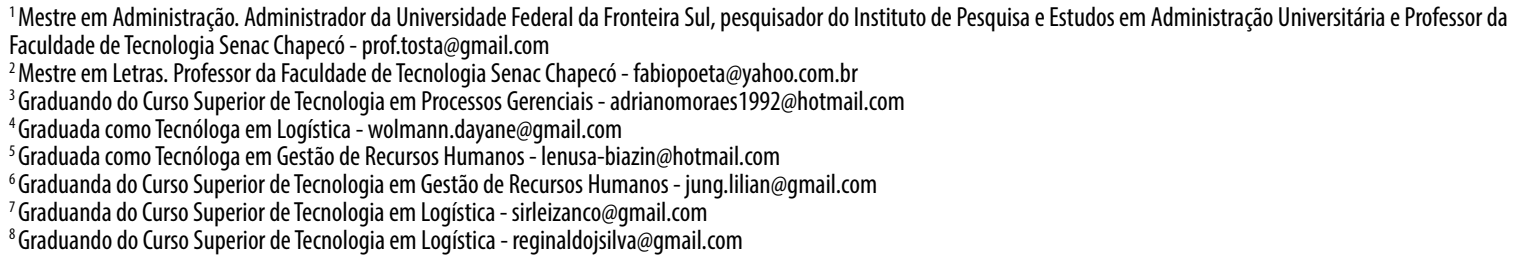


cursos de formação tecnológica.

Contudo, o atendimento às necessidades do mercado de trabalho pressupõe conhecimento de suas características, peculiaridades e demandas. Dessa forma, o presente estudo tem como pergunta norteadora: "Quais são as características do mercado de trabalho da microrregião de Chapecó que sinalizem a demanda por profissionais de nível superior tecnológico na área da gestão?".

\subsection{Objetivo geral}

Analisar as características do mercado de trabalho na microrregião de Chapecó/SC que sinalizem a demanda por profissionais de nível superior tecnológico na área de gestão.

\subsection{Objetivos específicos}

a) Identificar o perfil das indústrias da microrregião de Chapecó.

b) Revelar as áreas demandantes de profissionais de nível superior tecnológico na área da gestão.

\section{EXPLICITAÇÃO DO REFERENCIAL TEÓRICO}

Neste tópico, abordam-se temas relacionados ao mercado de trabalho, aos cursos superiores de tecnologia e à região Oeste de Santa Catarina.

\subsection{Mercado de trabalho}

As organizações vêm passando por um processo gradativo de mudanças - aumento da competitividade, inserção de novas tecnologias nos processos produtivos e automatização - as quais exigem novos diferenciais para permanecer nesse cenário competitivo. Desses fatores, porém, a grande dificuldade está na falta de profissionais qualificados para atender à necessidade do mercado (SOUZA, 2004).

0 desenvolvimento da sociedade nos níveis científicos e tecnológicos impôs à sociedade novas exigências quanto ao perfil dos profissionais, exigindo profissionais flexíveis e cada vez mais qualificados para interagir com a complexidade e quantidade de fatores que compõem o trabalho. Esse perfil é composto pelos conhecimentos, habilidades e atitudes cada vez mais perspicazes e propensos à adaptação. A dificuldade em encontrar profissionais com referido perfil vem gerando discussões em torno da formação e qualificação oferecida pelas instituições de ensino (GONDIM, 2002).

A globalização trouxe mudanças não somente no mercado competitivo, mas também no mercado de trabalho. Enquanto os países de primeiro mundo contam com profissionais altamente qualificados e com diferencial competitivo acrescentado às tecnologias e maquinário modernos, as linhas de produção no Brasil encontram-se despreparadas para atender à demanda por qualidade do mercado. Um dos fatores mais relevantes está no desemprego e na falta de qualificação. Tal situação converge para a necessidade de políticas governamentais voltadas para as questões educacionais e para os investimentos públicos em ensino técnico profissionalizante (MARRAS, 2009).

Com base nessa visão, percebe-se que a formação generalista e a experiência adquirida durante os cursos de graduação têm sido cada vez mais questionadas no que diz respeito à real competência e aptidão do profissional para ocupar vagas no mercado de trabalho. Segundo Gondim (2002), as empresas buscam no currículo dos profissionais, em sua formação acadêmica, características que propiciem um multiprofissional, com maturidade pessoal e identidade profissional capazes de enfrentar situações de imprevisibilidade e demais desafios presentes nas organizações atuais.

0 mercado de trabalho, de maneira geral, apresenta características altamente dinâmicas, pois é diretamente influenciado por fatores macroeconômicos, como taxa de crescimento do país, taxa de natalidade, choques tecnológicos, educacionais, entre outros, que impõem mudanças, sejam elas sutis ou substanciais. Os fatores microeconômicos, como idade, escolaridade, gênero, condição na família, região geográfica, entre outros, também contribuem para essa dinamicidade (SAMPAIO, 2012).

Tais mudanças, apresentadas pelo mercado de trabalho, têm exigido das empresas um grande esforço na busca pelos profissionais mais qualificados. As organizações com elevado crescimento enfrentam dificuldades em encontrar os talentos de que necessitam para expandir seus negócios, principalmente em cargos que exigem habilidades específicas, as quais representam desafios tanto para a empresa quanto para os profissionais (BOHLANDER; SNELL, 2011). 
Nesse contexto, na visão de Takahashi e Amorim (2008), um pilar central é o composto pelo setor educacional, pois, em tempos de globalização e níveis de competitividade altíssimos, as características dos mercados são extremamente mutáveis, o que resulta na necessidade da pesquisa e na formação de recursos humanos para compor os eixos centrais para o desempenho das empresas e das economias nacionais. A dinamicidade do mercado e o ingresso de novas tecnologias exigem dos profissionais novas competências, novas posturas.

Bitencourt (2001) corrobora com mencionada perspectiva ao considerar que as alterações contextuais das últimas décadas estimularam a valorização das pessoas, pois as organizações deparam-se com questões abrangentes e complexas e necessitam de respostas rápidas. Contudo, as mudanças exigem um novo posicionamento também das próprias pessoas diante dos novos desafios.

Nesse sentido, visualiza-se que "as novas formas de trabalho possuem um ponto comum, a necessidade de participação mais efetiva das pessoas tendo como base o desenvolvimento de conhecimentos, habilidades e atitudes, ou seja, desenvolvimento de competências" (BITENCOURT, 2001, p. 18.).

Em complemento, Takahashi e Amorim (2008) esclarecem que a tarefa posta para um dos segmentos do nível universitário, a educação tecnológica superior, é o preenchimento ágil e de qualidade de lacunas de mão de obra surgidas no mercado de trabalho por conta da chegada e disseminação de novas tecnologias.

Nas considerações de Takahashi e Amorim (2008), os cursos desse segmento vêm atender a uma demanda do mercado por especialistas dentro de uma área de conhecimento, em vez dos generalistas formados pelas outras modalidades de ensino superior. A educação tecnológica possui como característica o foco em determinadas áreas, a rapidez na formação e a inserção no mercado de trabalho. Ainda na concepção dos autores, a rápida inserção deve-se em grande medida ao direcionamento dos cursos às necessidades do mercado de trabalho que são identificadas por meio de pesquisas de mercado.

\subsection{Os cursos de nível tecnológico no contexto do mercado de trabalho atual}

A situação atual das organizações preconiza uma redefinição da realidade do mercado de trabalho considerando a relação entre a educação e a empregabilidade. Conforme a visão das organizações, os novos perfis profissionais devem abranger a polivalência e a flexibilidade. Os profissionais contemporâneos devem possuir tais características, bem como habilidades cognitivas e competências sociais para exercer suas funções nos mais diferentes ramos de atividade. Para isso, devem-se repensar as políticas de ensino e os programas de qualificação e requalificação das instituições de ensino (CATANI; OLIVEIRA; DOURADO, 2001).

Desse modo, o mercado de trabalho tem exigido uma reformulação e readequação da educação para atender às exigências atuais. Os principais fatores a serem analisados na elaboração dos cursos têm sido a dinâmica do curso, a sua adaptação às necessidades do mercado, a integração entre a graduação e a pósgraduação, além da ênfase no desenvolvimento de competências e habilidades que atendam a demanda. Nesse sentido, os cursos tecnológicos revelam-se os mais aprimorados e de acordo com as novas tendências do mercado, pois, desde sua metodologia, já são configurados com tais características (CATANI; OLIVEIRA; DOURADO, 2001).

A partir da análise do mercado de trabalho, pode-se perceber que este tem exigido cada vez mais profissionais com maior escolaridade e que estejam prontos para assumir os desafios cotidianos. Surge então o conceito dos cursos de modalidade tecnológica, cujo intuito é preencher vagas específicas do mercado e que são voltados ao mundo do trabalho, à inovação científica e tecnológica e à gestão de produção e serviços (TAKAHASHI, 2010).

Os cursos de nível tecnológico estão angariando cada vez mais espaço no cenário educacional brasileiro, tanto na rede pública quanto privada. Se aumentou o número dos cursos de bacharelado em administração, também cresceu consideravelmente o ingresso de alunos nos cursos tecnológicos em gestão. Esses cursos têm por finalidade formar profissionais nos mais diversos níveis e modalidades de ensino com foco variado dentro da economia, profissionais que venham a realizar pesquisas e desenvolvimento de projetos referentes a novos processos, produtos e serviços, sempre buscando o aperfeiçoamento do ensino e dos processos de trabalho (TAKAHASHI, 2010).

Na década de 1970, os cursos superiores de curta duração eram vistos como nível intermediário entre o curso técnico de nível médio e os de graduação, pois este se voltava a áreas específicas. Diferentemente dos bacharelados, que eram incumbidos de formar para o trabalho de concepção, os Cursos Superiores de Tecnologia (CSTs) têm por objetivo formar para o trabalho de operação e gestão. Sendo assim, no início, os tecnólogos sofreram grandes dificuldades para ingressar no mercado de trabalho. Os diplomados em cursos de duração plena demonstraram rejeição quanto ao ingresso dos tecnólogos, argumentando que estes não 
poderiam ser designados graduados em nível superior (MACHADO, 2008).

Segundo Takahashi (2010, p. 388), a principal diferença entre os cursos de graduação tecnológicos, que conferem o diploma de tecnólogo, e os cursos tradicionais de Ensino Superior, que conferem o diploma de licenciatura ou bacharel está

na proposta e nos propósitos de cada um. Os cursos tecnológicos vêm atender a uma demanda do mercado por especialistas dentro de uma área de conhecimento e estão orientados por características como foco, rapidez e flexibilidade, enquanto as outras modalidades de ensino superior visam formar generalistas.

O tecnólogo, como trabalhador qualificado, representa a dinâmica de formação de novas profissões e especialidades, encontrando-se no polo do sistema produtivo e tem muitas finalidades dentro da organização como, por exemplo, tornar realizáveis e viáveis projetos de processos e produtos; oferecer suportes à tomada de decisões e à definição de estratégias; orientar o manejo de equipamentos e instrumentos; tornar mais racional, eficiente e rentável os processos produtivos e os serviços; fazer avançar a funcionalidade, produtividade e a qualidade dos processos e produtos sem comprometer sua integridade e usabilidade; promover a otimização dos processos e sua visibilidade; contribuir para a sustentabilidade econômica, ambiental e social dos empreendimentos; e, aprimorar ações de preservação, proteção, prevenção, segurança e ergonomia (MACHADO, 2008).

De acordo com Machado (2008, p. 17), a atuação desse profissional teria diferentes cenários, espaços e segmentos, entre eles:

gestão, monitoramento e controle; consultorias, vistoria, perícia, prospecção, avaliação, assistência técnica e tecnológica; extração, tratamento e transformação de matériasprimas; construção, conservação e restauração; design e confecção; armazenagem, embalagem, movimentação, distribuição, suprimento, transporte e comercialização de produtos; pesquisa e desenvolvimento.

Dentro do contexto do mercado de trabalho, os cursos tecnológicos vêm representando uma oportunidade para os profissionais inserirem-se no mercado de trabalho, abrangendo instrumentos que lhe permitam interagir e desenvolver-se na sociedade da informação, do conhecimento e das novas tecnologias, correspondendo com as expectativas do mercado e cumprindo a legislação. Dessa forma, os cursos tecnológicos vêm para auxiliar tanto o mercado de trabalho, que está carente de mão de obra especializada, quanto os profissionais, que buscam rápida inserção e desenvolvimento profissional (TAKAHASHI, 2010).

Sobre a oferta dos cursos, o Ministério da Educação (MEC), por meio de sua Secretaria de Educação Profissional e Tecnológica, construiu o Catálogo Nacional dos Cursos Superiores de Tecnologia, que serve para "referenciar estudantes, educadores, instituições ofertantes, sistemas e redes de ensino, entidades representativas de classes, empregadores e público em geral" (BRASIL, 2010, p. 8).

Tal documento contém as características dos cursos bem como aquelas que se esperam de um profissional formado. Especificamente da área de gestão, constam no catálogo doze cursos, que visam atender às necessidades do mercado quanto às "tecnologias associadas aos instrumentos, técnicas e estratégias utilizadas na busca de qualidade, produtividade e competitividade das organizações" (BRASIL, 2010, p. 32).

\subsection{O contexto socioeconômico e de mercado de trabalho da região Oeste do Estado de Santa Catarina}

Tendo em vista que cada região apresenta suas peculiaridades quanto aos seus aspectos socioeconômicos e, consequentemente, às características de seu mercado de trabalho, convém apresentar o panorama atual da região Oeste de Santa Catarina, onde está inserida a microrregião de Chapecó, foco deste estudo. É mister destacar que esta análise se dará em um nível maior ao da microrregião, em virtude da indisponibilidade de dados específicos para tal.

Assim sendo, a região que compreende o Oeste catarinense, apresentava, em 2009, população estimada de 617.050 habitantes e era constituída de 58 municípios, sendo o mais populoso o de Chapecó, com 174.817 habitantes (SEBRAE, 2010). No que concerne à movimentação econômica, a região teve em $2006 \mathrm{a}$ movimentação financeira de R $\$ 8,9$ bilhões, o equivalente a 9,5\% do Produto Interno Bruto (PIB) estadual.

De acordo com dados da Federação das Indústrias do Estado de Santa Catarina (FIESC, 2012), o PIB da região foi, em 2009, de $\mathrm{R} \$ 11,5$ bilhões. Apesar do crescimento, a participação na riqueza estadual diminuiu, pois, nesse mesmo ano, correspondeu a 8,9\% do PIB estadual. 
Humberto Tonani Tosta; Fábio Martins Moreira; Adriano Moraes; Dayane da Silva Wolmann; Lenusa Paulina Biazin; Lilian Michele Jung; Sirlei Zanco Regoso; Reginaldo José da Silva

No que diz respeito ao cenário empresarial, o relatório Santa Catarina em Números, elaborado pelo Serviço Brasileiro de Apoio às Micro e Pequenas Empresas (SEBRAE, 2010), baseado em informações do Ministério do Trabalho e Emprego, referentes ao ano de 2008, revelou que a região Oeste do estado possuía 42.258 empresas, que geraram, no mesmo ano, 165.599 empregos formais. As cidades de Chapecó, Concórdia e Xanxerê, juntas, correspondiam a $60,2 \%$ dos empregos formais. Nesse cenário, as micro e pequenas empresas correspondiam a 95,1\% do total e aglutinavam a 51,5\% dos empregos formais (SEBRAE, 2010).

Segundo a FIESC (2012), os setores que mais possuíam estabelecimentos eram, respectivamente, comércio, serviço e indústria de transformação, e aqueles que continham o maior quantitativo de trabalhadores eram a indústria de transformação, serviços e comércio. Tal afirmação pode ser visualizada no Quadro 1.

Quadro 1 - Número de estabelecimentos e trabalhadores por atividade econômica em 2010

\begin{tabular}{ccc}
\hline Atividade econômica & Número de estabelecimentos* & Número de trabalhadores \\
\hline Agropecuária, extrativismo vegetal e pesca & 1.793 & 8.644 \\
Indústria extrativa mineral & 29 & 265 \\
Indústria de transformação & 3.459 & 77.777 \\
\hline Serviços industriais de utilidade pública & 139 & 2.431 \\
Construção civil & 1.894 & 15.990 \\
Comércio & 10.922 & 48.778 \\
Serviços & 9.633 & 74.976 \\
TOTAL & $\mathbf{2 7 . 8 6 9}$ & $\mathbf{2 2 8 . 8 6 1}$ \\
\hline
\end{tabular}

* Apenas os estabelecimentos que realizaram alguma movimentação de pessoal durante 0 ano (admitiram ou demitiram). Fonte: Adaptado de FIESC (2011)

Observa-se, portanto, uma inversão, pois, apesar de o setor comercial possuir o maior número de estabelecimentos, ele possui o terceiro maior quantitativo de profissionais.

Tendo sido caracterizada a região, na sequência são explicitados os aspectos metodológicos e técnicos.

\section{EXPLICITAÇÃO DOS PROCEDIMENTOS METODOLÓGICOS E TÉCNICOS}

De acordo com Vergara (2007), existem várias taxionomias para classificar os tipos de pesquisa. No entanto, a autora propõe dois critérios, os quais utilizamos neste estudo: quanto aos fins e quanto aos meios empregados.

Quanto aos fins, o presente estudo pode ser classificado como exploratório e descritivo. Exploratório, já que, na visão de Triviños (2009), permite ao investigador aumentar sua experiência em torno de determinado problema.

Caracteriza-se igualmente como descritiva, pois foi feita a análise do mercado de trabalho e reveladas as áreas profissionais de nível superior tecnológico demandadas. Conforme Gil (2002, p. 42), "as pesquisas descritivas têm como objetivo primordial a descrição das características de determinada população ou fenômeno ou, então, o estabelecimento de relação entre as variáveis".

Quanto aos meios de investigação que foram utilizados nesta pesquisa, podem ser classificados como bibliográfico e pesquisa de campo. Neste estudo, como em todas as pesquisas, a revisão teórica visa à construção de um marco teórico e maior familiaridade com o tema. Por fim, é uma pesquisa de campo, pois os dados foram levantados no próprio local onde os fenômenos acontecem.

$\mathrm{Na}$ primeira parte da pesquisa, os dados primários foram coletados pelo acesso à base de dados da Federação das Indústrias de Santa Catarina (FIESC) - o Guia Web SC -, num universo de todas as indústrias da microrregião, das seguintes informações: área de atuação, porte, números de empregados e ano de fundação. Tais dados permitiram traçar um perfil industrial da microrregião.

Num segundo momento, a coleta dos dados foi viabilizada por meio da aplicação de um questionário misto, contendo onze perguntas, das quais dez questões eram do tipo múltipla escolha, algumas com opções de justificativas, e uma aberta. 0 instrumento de coleta de dados foi encaminhado por e-mail aos gestores das indústrias da microrregião de Chapecó. Como a quantidade de respostas não foi suficente, em alguns casos, os pesquisadores foram pessoalmente às indústrias e, em outros, realizaram contatos telefônicos em 
busca de resposta, com os sujeitos da pesquisa.

Assim, do total de 298 indústrias da região, foram obtidas 66 respostas, sendo doze descartadas por apresentarem falhas no preenchimento. Das 54 respostas válidas, 49 são de indústrias de Chapecó.

Nos procedimentos de análise e interpretação dos dados, adotou-se a abordagem qualitativa e quantitativa, pelo uso da estatística descritiva, identificação do perfil do mercado de trabalho na microrregião de Chapecó e das áreas demandantes de profissionais de nível superior tecnológico.

A pesquisa qualitativa tem como característica o emprego de diferentes alegações de conhecimento, estratégias de investigação e métodos de coleta e análise de dados (CRESWELL, 2007). Destarte, a pesquisa quantitativa emprega a quantificação, tanto na coleta de dados quanto no tratamento por meio de técnicas estatísticas, que podem ser desde as mais simples, como percentual e média, às mais complexas, como coeficiente de correlação. É usualmente aplicada em estudos descritivos quando se procura descobrir e classificar a relação entre variáveis (RICHARDSON et al., 2008).

\section{APRESENTAÇÃO DOS RESULTADOS}

Neste tópico, apresenta-se o perfil das indústrias da microrregião de Chapecó, as áreas demandantes de profissionais egressos de cursos superiores de nível tecnológico e, ainda, a percepção dos gestores das referidas indústrias a respeito dessa modalidade de curso.

Com base nos dados da FIESC (2012), por intermédio de seu Guia Web SC, - catálogo das indústrias do estado -, disponibilizado on-line, observa-se que há uma grande variedade de indústrias na microrregião de Chapecó. Destas, porém, predominam as do ramo metalúrgico, com 55 unidades, seguidas por 38 do ramo mobiliário e construção civil e de produtos alimentares com 37, como pode ser observado no Gráfico 1.

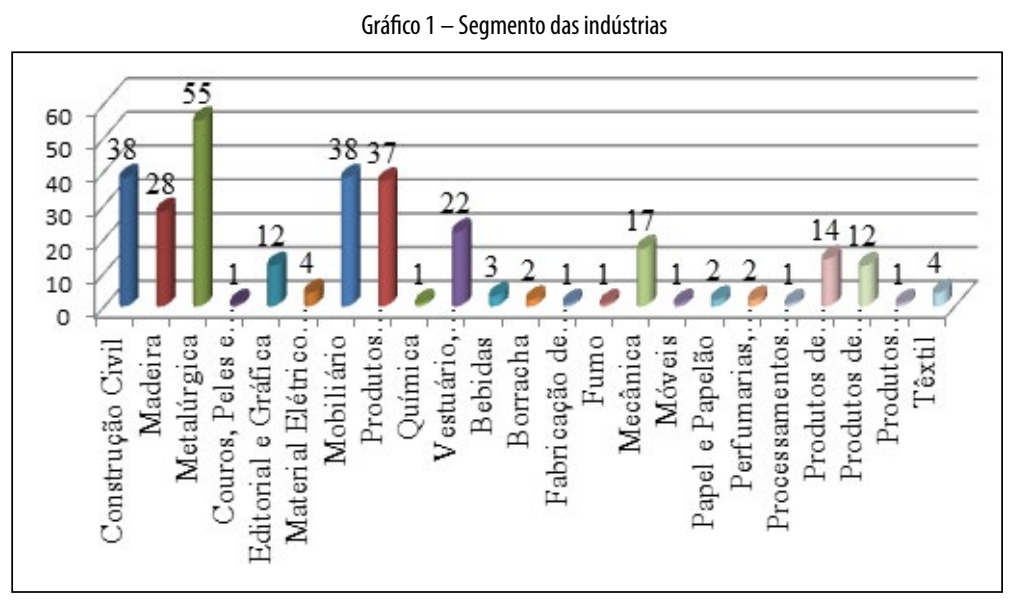

Fonte: Elaborado pelos autores (2012)

No Quadro 2, apresentam-se o número e o percentual de empresas instaladas nas cidades da microrregião. 
Humberto Tonani Tosta; Fábio Martins Moreira; Adriano Moraes; Dayane da Silva Wolmann; Lenusa Paulina Biazin; Lilian Michele Jung; Sirlei Zanco Regoso; Reginaldo José da Silva

\begin{tabular}{|c|c|c|}
\hline Cidade & $\begin{array}{l}\text { Número de indústrias por } \\
\text { cidade }\end{array}$ & $\begin{array}{c}\text { Porcentagem de indústrias na } \\
\text { microrregiāo }\end{array}$ \\
\hline Águas frias & 1 & $0,34 \%$ \\
\hline Caibi & 2 & $0,67 \%$ \\
\hline Campo Erê & 5 & $1,68 \%$ \\
\hline Caxambu do Sul & 6 & $2,01 \%$ \\
\hline Chapecó & 140 & $46,98 \%$ \\
\hline Cordilheira Alta & 3 & $1,01 \%$ \\
\hline Coronel Freitas & 15 & $5,03 \%$ \\
\hline Cunha Porã & 6 & $2,01 \%$ \\
\hline Guatambu & 3 & $1,01 \%$ \\
\hline Irani & 3 & $1,01 \%$ \\
\hline Jardinópolis & 1 & $0,34 \%$ \\
\hline Maravilha & 22 & $7,38 \%$ \\
\hline Modelo & 5 & $1,68 \%$ \\
\hline Nova Erechim & 7 & $2,35 \%$ \\
\hline Nova Itaberaba & 1 & $0,34 \%$ \\
\hline Palmitos & 9 & $3,02 \%$ \\
\hline Pinhalzinho & 33 & $11,07 \%$ \\
\hline Quilombo & 5 & $1,68 \%$ \\
\hline São Carlos & 8 & $2,68 \%$ \\
\hline São Lourenço d'Oeste & 16 & $5,37 \%$ \\
\hline Saudades & 5 & $1,68 \%$ \\
\hline Serra Alta & 2 & $0,67 \%$ \\
\hline Total geral & 298 & $100,00 \%$ \\
\hline
\end{tabular}

Fonte: Elaborado pelos autores (2012)

Visualiza-se, no Quadro 2, a cidade de Chapecó com número de indústrias bem maior que as demais, com um total de 140, equivalente a 46,98\%. Em seguida, ocupando o segundo lugar no ranking, está a cidade de Pinhalzinho, a qual concentra 33 empresas, representando 11,07\% das indústrias. A cidade de Maravilha, com suas 22 empresas e 7,38\% do total, figura como a terceira cidade com maior número de indústrias.

Com a visualização da quantidade de indústrias e sua distribuição na microrregião, o relatório elaborado com base em dados da FIESC apresenta um panorama da classificação das indústrias quanto ao porte. Como demonstra o Gráfico 2, a maioria (57\%) são de pequeno porte. As microempresas, geralmente familiares, compõem $27 \%$ do cenário industrial, seguidas pelas de médio porte, com um percentual de 12\%; somente $4 \%$ são de grande porte. 


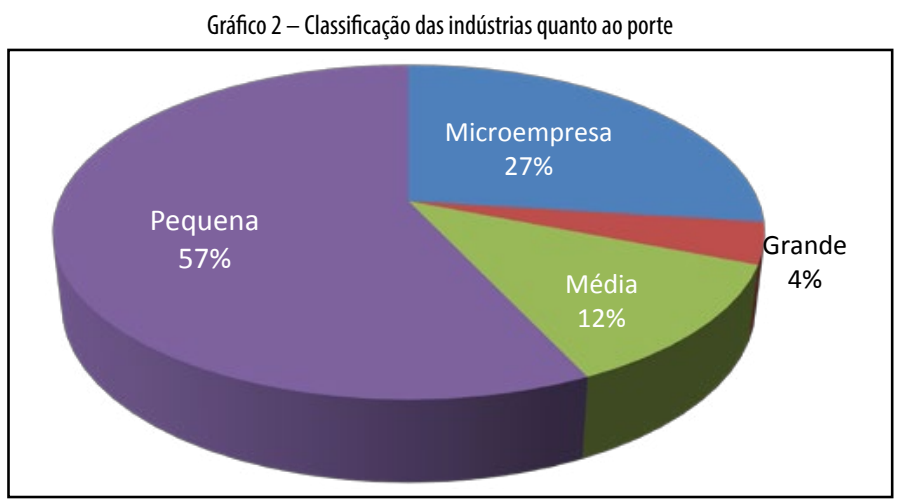

Fonte: Elaborado pelos autores (2014)

Outra informação revelada pela análise dos dados extraídos da base da FIESC é o tempo de atuação das indústrias no mercado. Conforme mostra o Gráfico 3, 134 empresas (44\%) estão no mercado entre dez a dezenove anos. Outras 101 (33\%) estão de vinte a 29 anos. As empresas que estão no mercado por um período de trinta a 39 anos somam 27 , totalizando $9 \%$ do total.

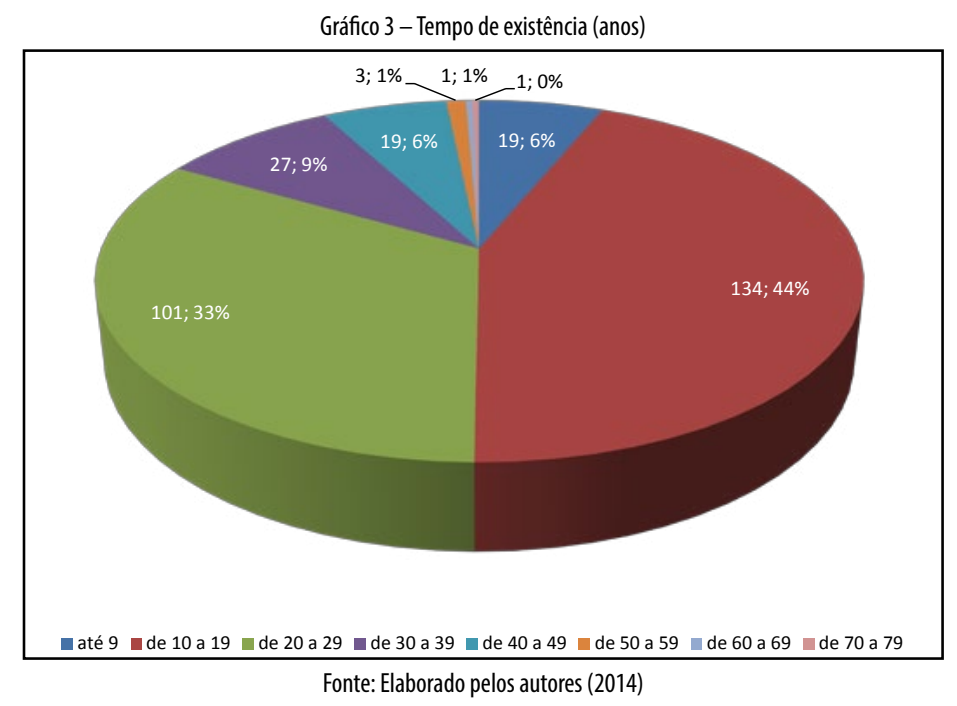

De acordo com a pesquisa realizada na microrregião de Chapecó, obteve-se 54 questionários respondidos. Com base nos dados, verificou-se que, entre os segmentos mais citados, estão as metalúrgicas, com dezessete respostas; construção civil, com oito; produtos alimentares, com sete; e as demais estão dispersas entre os dezenove segmentos restantes. Ainda foi citada a opção “outros" em quatro questionários; entretanto, não foi apresentada a área de atuação da indústria.

No que diz respeito ao porte dessas indústrias, constata-se que $27,77 \%$ dos questionários correspondem a microempresas; o mesmo percentual aparece nas indústrias de médio porte. Pode-se observar que as indústrias de pequeno porte representam 25,92\% dos resultados. Com relação às indústrias de grande porte, foi constatado ser a minoria dentre os resultados na microrregião de Chapecó, obtendo apenas $18,52 \%$ das repostas analisadas.

No que se refere ao porte das indústrias, ao comparar a microrregião integralmente, com aquelas participantes da pesquisa, verifica-se que essas indústrias são, em sua maioria, microempresa, ou empresa de médio porte. 
Humberto Tonani Tosta; Fábio Martins Moreira; Adriano Moraes; Dayane da Silva Wolmann; Lenusa Paulina Biazin; Lilian Michele Jung; Sirlei Zanco Regoso; Reginaldo José da Silva

Quadro 3 - Comparativo do percentual de porte de indústrias da microrregião e indústrias participantes da pesquisa

\begin{tabular}{|c|c|c|}
\hline Porte da Indústria & Perfil da Microrregião & Perfil das indústrias respondentes \\
\hline Microempresa & $27 \%$ & $27,77 \%$ \\
\hline Empresa de pequeno porte & $57 \%$ & $25,92 \%$ \\
\hline Empresa de médio porte & $12 \%$ & $27,77 \%$ \\
\hline Empresa de grande porte & $4 \%$ & $18,51 \%$ \\
\hline
\end{tabular}

Fonte: Elaborado pelos autores (2014)

Ao contrário do que se verifica no Quadro 3, no qual 57\% das indústrias são de pequeno porte, na pesquisa, a participação delas foi de quase $26 \%$. Isso se justifica pelo fato de a pesquisa ter utilizado amostragem não probabilística e por não ter havido foco em apenas um porte de indústrias.

Verificou-se igualmente a média de faturamento das indústrias entrevistadas.

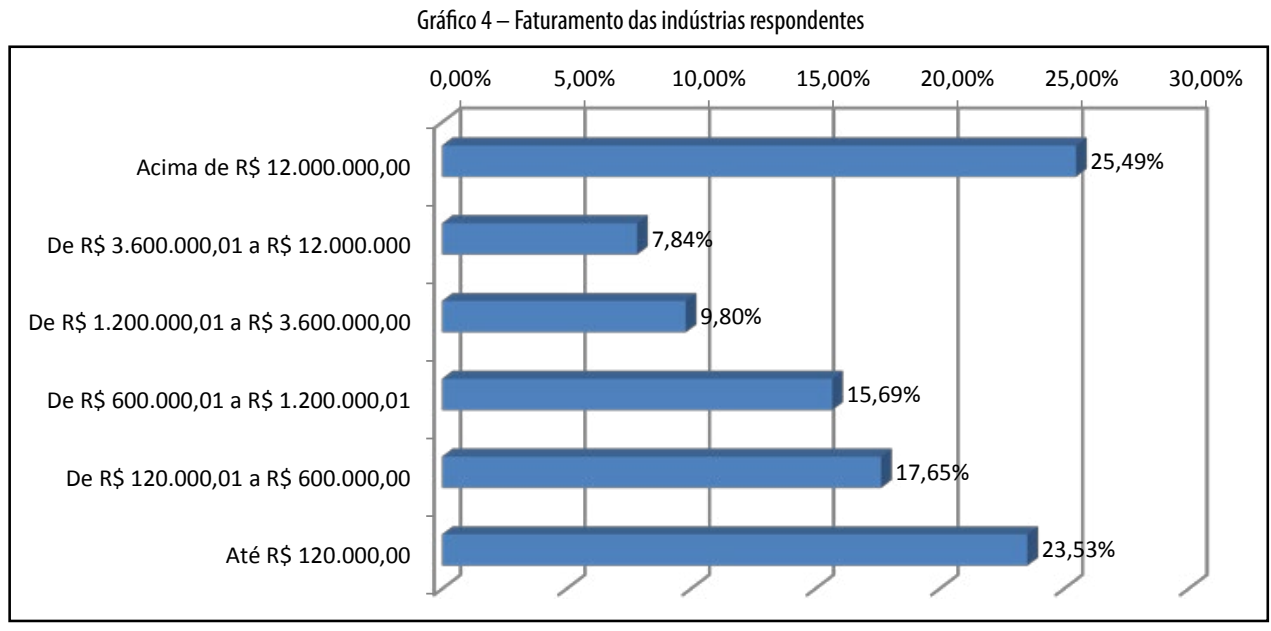

Fonte: Elaborado pelos autores (2012)

Em tal cenário, 24\% delas apresentam um faturamento anual acima de $\mathrm{R} \$ 12.000 .000,00$; outras - 22\% - indicaram o faturamento de até $\mathrm{R} \$ 120.000,00$. Observa-se que, para $17 \%$ das indústrias, a renda anual gira entre $\mathrm{R} \$ 120.000,01$ a $\mathrm{R} \$ 600.000,00$. Já em $15 \%$ das indústrias, o faturamento anual possui marcadores entre $\mathrm{R} \$ 600.000,01$ a $\mathrm{R} \$ 1.200 .000,00$. Também é possível identificar em 9\% das entrevistadas, que o montante anual tem valores na casa de $\mathrm{R} \$ 1.200 .000,01$ a $\mathrm{R} \$ 3.600 .000,00$. E, em apenas $7 \%$ dos casos, as indústrias apresentam a variação de faturamento anual de $R \$ 3.600 .000,01$ a $R \$ 12.000 .000,00$. Não foi possível obter o faturamento anual de três indústrias, pois não divulgaram respostas.

No que concerne à quantidade de funcionários, para a amostra estudada, 35\% empregam até dezenove pessoas; outras 35\% empregam de vinte a 99 funcionários. Em 19\% dos demais casos, é possível constatar que a indústria possui de cem a 499 empregados e, por fim, outros 11\% são representativos de grandes empresas, que contratam mais de quinhentos funcionários.

De acordo com SEBRAE (2013), as indústrias, quanto ao número de funcionários, são classificados em:

- Microempresa: até dezenove funcionários.

- Pequena empresa: de vinte a 99 funcionários.

Com isso, na referida classificação, percebe-se que 70\% das indústrias são micro ou pequena empresa, pois empregam no máximo 99 funcionários.

Visando atingir o segundo objetivo desta pesquisa, perguntou-se aos gestores quais seriam as áreas para as quais suas indústrias demandariam profissionais de curso superior tecnológico capacitados. Para responder a tal questionamento, as opções eram os cursos da área de gestão disponível no Catálogo Nacional de Cursos Superiores de Tecnologia, publicado pelo Ministério da Educação. Assim sendo, tem-se no Quadro 4 o resultado de tal questionamento. 
Humberto Tonani Tosta; Fábio Martins Moreira; Adriano Moraes; Dayane da Silva Wolmann; Lenusa Paulina Biazin; Lilian Michele Jung; Sirlei Zanco Regoso; Reginaldo José da Silva

Quadro 4 - Áreas demandantes de profissionais de curso superior tecnológico na microrregião

\begin{tabular}{|c|c|c|}
\hline CURSO & RESPOSTAS & \% RESPOSTAS \\
\hline Gestão de Pessoas & 21 & 17,21 \\
\hline Logística & 7 & 5,74 \\
\hline Gestão Financeira & 20 & 16,39 \\
\hline Marketing & 8 & 6,56 \\
\hline Gestão da Qualidade & 13 & 10,66 \\
\hline Processos Gerenciais & 12 & 9,84 \\
\hline Gestão Comercial & 12 & 9,84 \\
\hline Gestão da Tecnologia da Informação & 10 & 8,20 \\
\hline Comércio Exterior & 2 & 1,64 \\
\hline Outros & 17 & 13,93 \\
\hline Total & 122 & 100 \\
\hline
\end{tabular}

Fonte: Elaborado pelos autores (2012)

Segundo os gestores entrevistados, existem certas áreas que mais demandam profissionais capacitados com nível superior tecnológico. Por isso, para responder à referida questão, as indústrias podiam marcar mais de um item.

A área de gestão de pessoas foi a mais mencionada, com 17,21\%; seguida da gestão financeira com 16,39\%. 0 setor da gestão da qualidade aparece com 10,66\%. Também foram citados processos gerenciais e gestão comercial com 9,84\%; e, com 8,20\%, a gestão da tecnologia da informação. A logística apresenta $5,74 \%$, e, por fim, o comércio exterior, com 1,64\%.

Também no que tange às áreas demandantes, 13,93\% das respostas foram na opção 'outras', e houve ainda indicação de quais seriam essas necessidades profissionais específicas, que não se encaixavam nas opções apresentadas. No entanto, o que se verificou foi a falta de entendimento dos respondentes na diferença entre curso superior tecnológico e curso técnico. Além do mais, obteve-se impasse na diferenciação dos cursos superiores tecnológicos da área de gestão e industrial. Essa inferência pode ser reforçada pela indicação de cursos como agronomia, veterinária, alimentos, engenharia, gestão da produção, segurança do trabalho, entre outros, que não compõem o rol de cursos de gestão, em nível tecnológico.

A respeito da influência do tempo de duração do curso no momento da contratação, dos 54 questionários respondidos, 29 respondentes disseram não levar em conta esse tipo de aspecto na hora da seleção do funcionário. Em outras 21 respostas, foi respondido como 'indiferente', e apenas em quatro indústrias constatou-se que o tempo de duração influencia para contratação de funcionários.

Ao perguntar se a empresa contrata ou contrataria um profissional formado em um curso superior de nível tecnológico, a maioria das empresas entrevistadas respondeu que sim, pois esse profissional estará mais bem qualificado para o mercado de trabalho, expondo ideias para a redução de custos e obtendo maior lucratividade. Apenas quatro sujeitos afirmaram que não contratariam, por possuir uma empresa familiar, que, na sua concepção, não suporta ou não necessita de um profissional de formação especializada.

A respeito da formação especializada em uma área de gestão, correlacionada com as necessidades de mercado, proporcionada pela natureza do curso superior tecnológico, diagnosticou-se, em 37 respostas, a percepção de que há sim um diferencial competitivo ao postulante a uma vaga de emprego, pois, possibilitase um maior conhecimento na área de formação, com o objetivo de suprir e desenvolver habilidades focando em pontos carentes da empresa. Contudo, para dezessete dos entrevistados, a resposta assinalada foi 'indiferente', o que vai diferenciar é o empenho em que o contratado terá para prestar o serviço.

Em trinta indústrias, não há profissionais formados em algum curso superior tecnológico, mas 24 estabelecimentos empresariais alegaram possuir funcionários formados em determinada especificação tecnológica, como, por exemplo, em processos gerenciais, gestão de pessoas, logística e tecnologia da informação. Porém, essa informação necessita ser analisada com cautela, uma vez que se percebeu haver ainda certa dificuldade dos respondentes em diferenciar a formação técnica (ensino médio) da formação tecnológica (ensino superior).

Relativamente aos principais fatores levados em consideração na hora de contratar um profissional egresso de um curso superior tecnológico, percebe-se, em uma escala de um a cinco, que a "formação 
prática" e "formação teórica alinhada à prática profissional" são características consideradas relevantes para os entrevistados e que são diferenciais, pois os levariam a contratar um profissional egresso.

Já na "visão inovadora", as respostas não indicam que seria esse um fator determinante para a contratação, assim como, o "contato direto com as modernas tecnologias de apoio à tomada de decisão na área de formação". Por fim, a "formação específica em uma área de gestão" aparenta ser importante, mas não é possível afirmar, pois sua média ficou em 2,96, ou seja, um valor intermediário.

De acordo com 52 indústrias, não há impeditivos para contratar egressos de curso superior tecnológico. Os entrevistados afirmam que tais profissionais atendem em certas áreas à expectativa da empresa e geram um custo-benefício favorável. Somente uma minoria acredita que cursos muito curtos não representam ser muito eficientes em termos de conhecimento.

\section{CONSIDERAÇÕES FINAIS}

Com as diversas mudanças no mercado de trabalho e a difícil tarefa de contratar profissionais competentes, as indústrias estão investindo nos profissionais tecnólogos, pois estes possuem seus conhecimentos voltados para a área específica, com formação voltada ao mercado de trabalho. Todavia, percebe-se que ainda há concepções antigas que expressam o curso superior de tecnologia, como cursos técnicos voltados para o setor operacional. No entanto, conforme vai se expandindo, passam a ser reconhecidos como ensino superior de graduação.

Verifica-se que a inserção dos egressos tecnólogos está sendo mais aceita, e esses profissionais já estão tornando-se percebidos no mercado. Isso mostra que o conhecimento adquirido nas instituições de cursos de tecnólogos também ganha legitimidade da comunidade.

Ao direcionar a pesquisa para as indústrias, ficou nítida a falta de profissionais qualificados na produção, já que houve grande abertura dos entrevistados para o ingresso de profissionais com curso técnico nessas áreas. Contudo, há uma necessidade em se obter gestores capacitados para liderar, organizar e coordenar a área produtiva, para que, assim, se possa ampliar toda a empresa atingindo o sucesso almejado.

Este estudo indicou a expansão e desenvolvimento das indústrias da microrregião de Chapecó. Um exemplo notável é o valor anual de faturamento, embora foram verificados perfis predominantes de micro e pequenas empresas, se considerado o número de funcionários.

Relativamente ao reconhecimento dos cursos superiores de tecnologia com foco na área de gestão, esta pesquisa sinalizou a demanda por profissionais de gestão de pessoas, processos gerenciais, tecnologia da informação, gestão financeira, gestão da qualidade, gestão comercial, assim como a logística. Isso comprova o real interesse entre as empresas, especialmente as indústrias, para com a modernização e a busca pela vantagem competitiva em um mercado complexo e carente de profissionais capacitados.

\section{ACCEPTANCE OF TECHNOLOGISTS IN THE JOB MARKET: THE REALITY IN THE MICROREGION OF CHAPECÓ-SC}

\section{ABSTRACT}

This research aims to analyze the characteristics of the job market in the microregion of Chapecó - SC, and more specifically to investigate the demand for management professionals of technological higher education in the microregion of Chapecó, located in the West of Santa Catarina.It is a study of qualitative and quantitative nature. Regarding purpose, it is an exploratory and descriptive research. Data analysis applied descriptive statistics and qualitative interpretations. The research showed a demand for professionals holding a degree in technological higher education in the areas of people management, management processes, technology of information financial management, quality management, commercial management and logistics. The results indicate an interest among businessmen, mainly in industries, towards modernization and the pursuit of competitive advantage through the hiring of qualified professionals

Keywords: Job market. Technological higher education course. Microregion of Chapecó-SC. 


\section{REFERÊNCIAS}

BITENCOURT, Cláudia Cristina. A gestão de competências gerenciais: a contribuição da aprendizagem organizacional. 2001. Tese (Doutorado) - Universidade Federal do Rio Grande do Sul, Porto Alegre, 2001. Disponível em: <http://www.lume.ufrgs.br/handle/10183/1793>. Acesso em: 9 set. 2010.

BOHLANDER, George; SNELL, Scott. Administração de recursos humanos. São Paulo: Cengage Learning, 2011.

BRASIL. Catálogo Nacional de Cursos Superiores de Tecnologia. Brasília, DF: MEC/INEP, 2010. Disponível em:

< http://portal.mec.gov.br/index.php?Itemid=86\&id=12352\&option=com_content\&view=article $>$. Acesso em: 21 jun. 2014.

CATANI, Afrânio Mendes; OLIVEIRA, João Ferreira de; DOURADO, Luiz Fernandes. Política educacional, mudanças no mundo do trabalho e reforma curricular dos cursos de graduação no Brasil. Educação \& Sociedade, v. 22, n. 75, p. 67-83, ago. 2001. Disponível em: <http://www.scielo.br/pdf/es/ v22n75/22n75a06.pdf>. Acesso em: 24 out. 2012.

CRESWELL, John W. Projeto de pesquisa: métodos qualitativo, quantitativo e misto. 2. ed. Porto Alegre: Artmed, 2007.

FEDERAÇÃO DAS INDÚSTRIAS DO ESTADO DE SANTA CATARINA (FIESC). Santa Catarina em dados. Florianópolis: FIESC, 2011.

FEDERAÇÃO DAS INDÚSTRIAS DO ESTADO DE SANTA CATARINA (FIESC). Guia Web SC. Disponível em: <http://www.fiescnet.com.br/guiawebsc> Acesso em: 18 out. 2012.

GIL, Antonio Carlos. Como elaborar projetos de pesquisa. São Paulo: Atlas, 2002.

GONDIM, Sônia Maria Guedes. Perfil profissional e mercado de trabalho: relação com a formação acadêmica pela perspectiva de estudantes universitários. Estudos de Psicologia, v. 7, n. 2, p. 299-309, 2002. Disponível em: <http://www.scielo.br/pdf/\%0D/epsic/v7n2/a11v07n2.pdf>. Acesso em: 24 out. 2012.

MACHADO, Lucília Regina de Souza. O profissional tecnólogo e sua formação. Revista da RET - Rede de estudos do trabalho, v. 2, n. 3, p. 2-28, 2008. Disponível em: <http://www.estudosdotrabalho.org/ LuciliaMachado.pdf>. Acesso em: 24 out. 2012.

MARRAS, Jean Pierre. Administração de recursos humanos: do operacional ao estratégico. 13. ed. São Paulo: Futura, 2009.

RICHARDSON, R. J. et al. Pesquisa Social: métodos e técnicas. 3. ed. São Paulo: Atlas, 2008.

SAMPAIO, Armando Vaz. Estrutura do mercado de trabalho metropolitano na Região Sul do Brasil, em 1995 e em 2005. Revista Nova Economia, Belo Horizonte, v. 22, p. 85-115, jan./abr. 2012.

SEBRAE. Santa Catarina em números. Florianópolis: Sebrae/SC, 2010. 127p. Disponível em: <http:// www.sebrae-sc.com.br/scemnumero/arquivo/Documento-Estadual.pdf>. Acesso em: 4 jul. 2013.

SEBRAE. Critérios e conceitos para classificação de empresas. Disponível em: <http://www.sebrae. com.br/uf/goias/indicadores-das-mpe/classificacao-empresarial>. Acesso em: 30 jan. 2013.

SOUZA, José dos Santos. Trabalho, qualificação, ciência e tecnologia no mundo contemporâneo: fundamentos teóricos para análise da política de educação profissional. Revista da FAEEBA - Educação e contemporaneidade, Salvador, v. 13, n. 22, p. 1-15, jul./dez., 2004. Disponível em: <http://www.ia.ufrrj.br/ ppgea/conteudo/conteudo-2008-2/Educacao-MII/2SF/6-Souza2005.pdf>. Acesso em: 24 out. 2012. 
Humberto Tonani Tosta; Fábio Martins Moreira; Adriano Moraes; Dayane da Silva Wolmann; Lenusa Paulina Biazin; Lilian Michele Jung; Sirlei Zanco Regoso; Reginaldo José da Silva

TAKAHASHI, Adriana R. W. Cursos superiores de tecnologia em gestão: reflexões e implicações da expansão de uma (nova) modalidade de ensino superior em administração no Brasil. Rev. Adm. Pública, Rio de Janeiro, v. 44, n. 2, p. 385-414, mar./abr. 2010. Disponível em: <http://www.scielo.br/pdf/rap/ v44n2/09.pdf>. Acesso em: 4 jul. 2013.

TAKAHASHI, Adriana R. W.; AMORIN, Wilson A. C. Reformulação e expansão dos cursos superiores de tecnologia no Brasil: as dificuldades da retomada da educação profissional. Revista Ensaio, Rio de Janeiro, v. 16 , n. 59 , p. $207-228$, abr./jun. 2008.

TRIVIÑOS, Augusto N. S. Introdução à pesquisa em ciências sociais. São Paulo: Atlas, 2009.

VERGARA, Sylvia Constant. Projetos e relatórios de pesquisa em administração. 9. ed. São Paulo: Atlas, 2007. 